\title{
Multiple Band-Notched UWB Antenna with Band-Rejected Elements Integrated in the Feed Line
}

\author{
Fuguo Zhu, Steven Gao, Member, IEEE, Anthony TS Ho, Senior Member, IEEE, Raed A. Abd-Alhameed, Chan H. \\ See, Tim WC Brown, Member, IEEE, Jianzhou Li, Gao Wei, and Jiadong Xu
}

\begin{abstract}
To mitigate potential interferences with coexisting wireless systems operating over 3.3-3.6 GHz, 5.15-5.35 GHz, or 5.725-5.825 GHz bands, four novel band-notched antennas suitable for ultra-wideband (UWB) applications are proposed. These include UWB antennas with a single wide notched band, a single narrow notched band, dual notched bands, and triple notched bands. Each antenna comprises a half-circle shaped patch with an open rectangular slot and a half-circle shaped ground plane. Good band-notched performance is realized by using high permittivity and low dielectric loss substrate, and inserting quarter-wavelength horizontal/vertical stubs or alternatively embedding quarter-wavelength open-ended slots within the feed line. The results of both simulation and measurement confirm that the gain suppression of the single and multiple band-notched antennas in each desired notched band are over $15 \mathrm{~dB}$ and $10 \mathrm{~dB}$, respectively. The radiation pattern of the proposed triple band-notched design is relatively stable across the operating frequency band.
\end{abstract}

Index Terms - UWB antenna, band-notched characteristic, gain suppression, quarter-wavelength band-rejected elements

\section{INTRODUCTION}

$\mathrm{U}$ WB communication systems have attracted considerable attention due to the advantages of high speed data rate and extremely low spectral power density, since the Federal Communications Commission (FCC) first approved the frequency band from 3.1 to $10.6 \mathrm{GHz}$ for commercial UWB applications in 2002 [1]. This has increased the demands on the UWB systems and subsequently to stimulate the research activities in various UWB antenna designs [1-3]. Challenges of the feasible UWB antenna design include the wide impedance matching, radiation stability, low profile, compact size, and low cost for consumer electronics applications. In the designated UWB operating band, several narrowband wireless standards have been allocated to share some parts of this spectrum. These include Worldwide Interoperability for Microwave Access (WiMAX) service (3.3-3.6 GHz) and Wireless Local Area

F. Zhu and S. Gao are with Surrey Space Centre, University of Surrey, Guildford, GU2 7XH, UK (f.zhu@ surrey.ac.uk; s.gao@ surrey.ac.uk).

A. TS Ho is with the Department of Computing, University of Surrey, Guildford, GU2 7XH, UK (A.Ho@surrey.ac.uk).

R. A. Abd-Alhameed and C. H. See are with Antennas and Applied Electromagnetics Research Group, University of Bradford, Bradford, BD7 1DP, UK (r.a.a.abd@bradford.ac.uk, c.h.see2@bradford.ac.uk).

T. Brown is with Centre for Communication Systems Research, University of Surrey, Guildford, GU2 7XH, UK (T. Brown@ surrey.ac.uk)

J. Z. Li, G. Wei and J. D. Xu are with Northwestern Polytechnical University, Xi'an, 710072, P.R. China (ljz@nwpu.edu.cn, weigao@nwpu.edu.cn, jdxu@nwpu.edu.cn).
Network (WLAN) services IEEE802.11a (5.15-5.35 GHz and 5.725-5.825 GHz) [4], which might potentially interfere with the UWB systems. Hence, it is desirable for UWB antennas to perform the band-notched function to mitigate the unwanted interferences from these coexisting wireless systems and remove the requirement of an additional band-stop filter.

In the literature, various techniques have been applied in the UWB antenna to achieve the single band-notched function [5-20]. The most popular approaches to achieve band-notched designs were embedding half-wavelength slots with different shapes, i.e., U-shaped [7-8], C-shaped [9], and arc-shaped [10-11], quarter-wavelength open-ended slots [11-13] on the radiating patch or its ground plane, and utilizing half-wavelength parasitic elements near the radiator [14-15] or feed line [16]. Compared to the half-wavelength slots or strips, the quarter-wavelength open-ended slots require less space and are promising for designing multiple band-notched antennas as it is difficult to apply multiple half-wavelength slots or strips due to the limited space available within the antenna structure. Though lots of single band-notched UWB antennas have been reported in the literature, most of the existing designs have limited gain suppression in the notched band, i.e., $<10 \mathrm{~dB}$ [10-12], [15-16], or < $5 \mathrm{~dB}$ [7-9], [13-14], [17].

Recently, several multiple band-notched UWB antennas have been reported in [4], [21-26]. Some designs with dual band-notched property are achieved by utilizing a couple of half-wavelength parasitic elements in an open rectangular slot [21], embedding dual C-shaped slots on the radiator [22], or inserting dual quarter-wavelength stubs [23]. Moreover, the triple band-notched function was also studied in [24] by using the combination of a quarter-wavelength open-ended slot and half-wavelength slots on the radiator. However, the above designs have limited band-notched performance (VSWR < 10) [21-22, 24] at each notched frequency or limited gain suppression $(<10 \mathrm{~dB})$ in the notched band [21-23]. To obtain a better triple band-notched performance, authors in [4] have proposed adding three capacitively loaded loop (CLL) resonators close to the feed line. It was found good band-notched performance at one notched frequency while limited band-notched performance at other notched frequencies. In [25], a dual band-notched UWB antenna employing electromagnetic band-gap (EBG) structures near the feed line was also proposed. However, it had limited band-notched performance due to the dielectric loss of the substrate. Another method was suggested in [26], which had introduced a substrate integrated waveguide (SIW) cavity within the feed line of an UWB monopole antenna to obtain multiple band-notched functions. This approach has acceptable band-notched 
performance at each notched frequency. However, it may lead to increasing the size and complexity of the antenna.

In this paper, four novel coplanar waveguide (CPW)-fed UWB antennas with band-notched characteristics are presented. By integrating the band-rejected elements with the antenna, the proposed designs can reject the frequency bands in 3.3-3.6 $\mathrm{GHz}, 5.15-5.35 \mathrm{GHz}$ or $5.725-5.825 \mathrm{GHz}$ without using an additional band-stop filter. Good band-notched performance with a high level of signal rejection can be achieved by inserting the quarter-wavelength band-rejected elements within the signal line and adopting high permittivity substrate. The whole process starts from the design of the reference UWB antenna (without notched band) and then followed by investigating the single wide/narrow band notched UWB antenna. Next, the dual band-notched UWB antenna is proposed based on the single narrow band-notched antenna. Finally, the triple band-notched UWB antenna is devised based on the previous design steps. The results of reflection coefficient, input impedance, equivalent circuit models, radiation patterns and gain response are illustrated and discussed in detail.

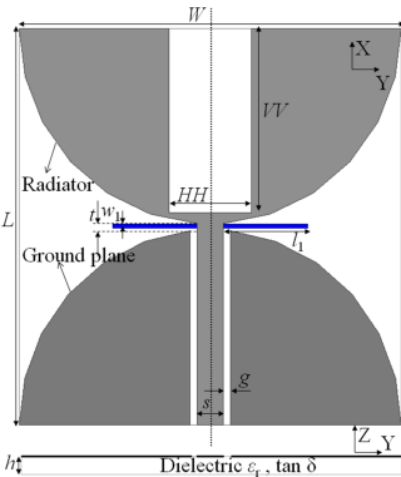

(a)

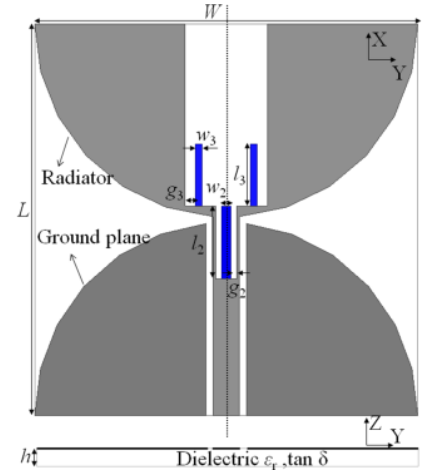

(c)

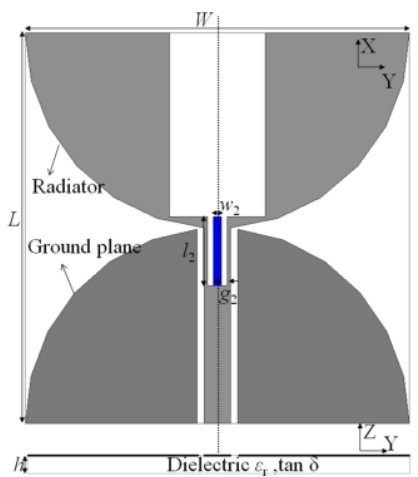

(b)

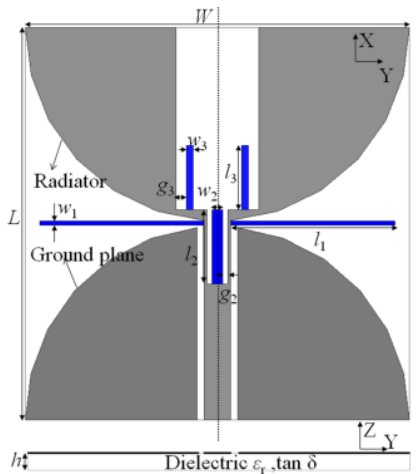

(d)
Fig. 1 Configurations of the proposed UWB antennas with (a) single wide notched band (Antenna I_W), (b) single narrow notched band (Antenna I_N), (c) dual notched bands (Antenna II), and (d) triple notched bands (Antenna III).
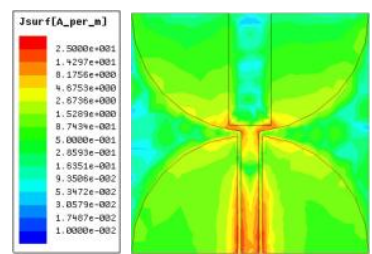

(a)

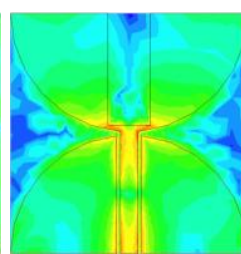

(b)

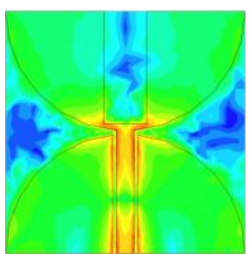

(c)
Fig. 2 Surface current distributions on the reference antenna (without notch) at (a) $3.5 \mathrm{GHz}$, (b) $5.2 \mathrm{GHz}$ and (c) $5.8 \mathrm{GHz}$.

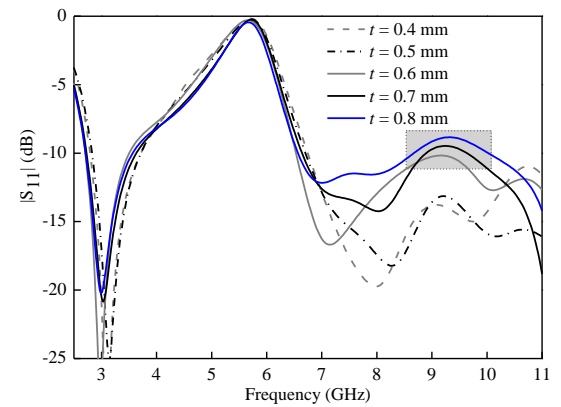

Fig. 3 Variation of reflection coefficient in terms of $t$.

\section{SINGLE BAND-NOTCHED UWB ANTENNA DESIGN}

In order to avoid interferences with the WLAN band, two single band-notched designs are presented and analyzed in this section. A wide band covering both the lower and upper WLAN bands is notched in one design (Antenna I_W), whereas a narrow band-notched function in the upper WLAN band is obtained in the other antenna design (Antenna I_N).

\section{A. UWB Antenna with Wide Band-Notched Function (Antenna $\left.I \_W\right)$}

In the following discussion, an antenna with the desired UWB properties but no additional band-stop structure is used as a reference antenna. This is identical to Fig. 1(a) except that it does not include the two horizontal strips at the center, in which, the $x z$ - and $y z$ - planes referred to E- and H-planes of this antenna. The complex impedance of the reference antenna is denoted $Z a$ throughout. It is printed on a 0.635 -mm thick Rogers 6010 substrate with the dielectric constant $\varepsilon_{\mathrm{r}}=10.2$ and loss $\operatorname{tangent} \tan \delta=0.0023$. This antenna is symmetric about its center line, and consists of a half-circle shaped radiator with an open rectangular slot and a half-circle shaped ground plane. The monopole is fed using a CPW transmission line. Given the $\mathrm{CPW}$-line an impedance of $50 \Omega$, the width of the signal line is $s$ $=1.93 \mathrm{~mm}$ and the two longitudinal gaps are $g=0.5 \mathrm{~mm}$. In designing the antenna, the lowest operating frequency $f_{l}$ can be empirically predicted by the following formula [27]

$$
\begin{gathered}
f_{l} \approx \frac{c}{4 \sqrt{\varepsilon_{\text {eff }}} \times \frac{L}{2}} \\
\varepsilon_{\text {eff }}=\frac{\varepsilon_{r}+1}{2}
\end{gathered}
$$

where $c$ and $\varepsilon_{e f f}$ are the speed of light in free space and the approximated effective dielectric constant, respectively. $L$ is the length of the antenna. It is worthwhile to note that, the rectangular slot with dimensions of $V V \times H H$ where the current is minimal plays a role in accommodating the band-notched elements without impair the impedance matching [27]. To further examine the possible locations for inserting the band-notched elements, the current distributions of the reference UWB antenna at desired frequencies, i.e., $3.5 \mathrm{GHz}$, $5.2 \mathrm{GHz}$ and $5.8 \mathrm{GHz}$ are depicted in Fig. 2. As can be seen, the current distributions are mainly concentrated in the signal line and near the gap between the radiator and the ground plane. These sensitive locations therefore have been selected for the band-notched elements in this presented work. 
In order to achieve good band-notched performance, two strips are horizontally connected to the signal line which has strong current flows and symmetrically placed to the center line of the antenna. The single band-notched antenna is denoted as

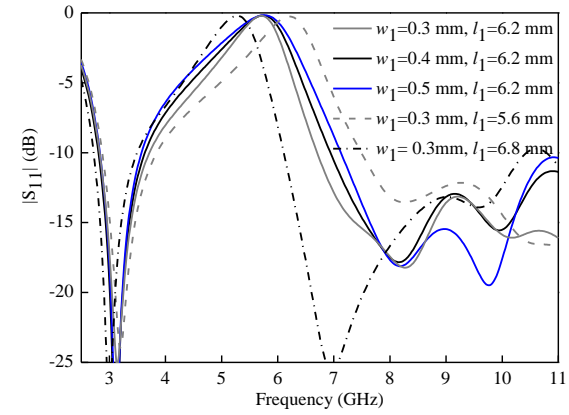

Fig. 4 Variation of reflection coefficient in terms of $w_{1}$ and $l_{1}$.

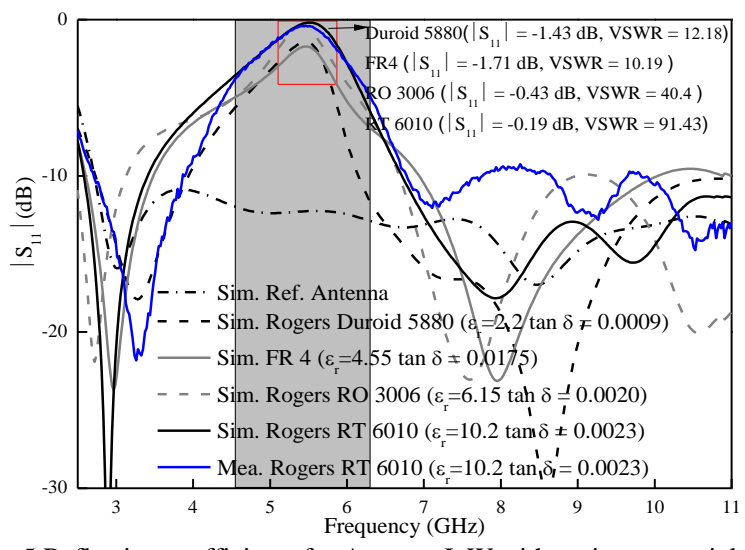

Fig. 5 Reflection coefficients for Antenna I_W with various materials.

Antenna I_W. The strips resemble a band-rejected filter to suppress the unwanted frequency band. The band-notched characteristics at the desired frequency can be obtained when adjusting the length of the strip to be approximately a quarter-wavelength. The optimized values of the antenna dimensions assuming $f_{l}=3.1 \mathrm{GHz}$ and the notched frequency $f_{n}$ $=5.5 \mathrm{GHz}$ are as follows: $W=28 \mathrm{~mm}, L=28.5 \mathrm{~mm}, H H=6$ $\mathrm{mm}, V V=13.2 \mathrm{~mm}, t=0.5 \mathrm{~mm}, l_{1}=6.2 \mathrm{~mm}, w_{1}=0.3 \mathrm{~mm}, s=$ $1.93 \mathrm{~mm}, g=0.5 \mathrm{~mm}$. The effects of three different parameters $t, w_{1}$ and $l_{1}$ on the reflection coefficient of the presented design are studied and shown in Figs. 3-4, respectively, where $t$ is the gap between the radiator and the ground plane, $w_{1}$ and $l_{1}$ are the width and length of the strip. In Fig. 3, a wide notched band is obtained over the UWB frequency band when $t$ is changing from 0.4 to $0.8 \mathrm{~mm}$. Interestingly, it is also found that the performance of the reflection coefficient near $9 \mathrm{GHz}$ becomes poor when $t$ is larger than $0.5 \mathrm{~mm}$. Taking the consideration of the performance and limited space for inserting the band-rejected elements, $0.5 \mathrm{~mm}$ is chosen for $t$ in the design. As observed in Fig. 4 that, the notched frequency is shifted from 6.2 to $5.28 \mathrm{GHz}$ when $l_{1}$ increases from 5.6 to $6.8 \mathrm{~mm}$. Moreover, the increase in the bandwidth of the notched band can be observed when $w_{1}$ increases from 0.3 to $0.5 \mathrm{~mm}$. It should be highlighted that, the value less than $0.3 \mathrm{~mm}$ is not considered to avoid the fabrication error. Since the notched band can cover $5-6 \mathrm{GHz}$ when $w_{1}$ is equal to $0.3 \mathrm{~mm}$, the width of the horizontal stub is selected to be $0.3 \mathrm{~mm}$.
The variation of the permittivity of the substrate against the reflection coefficient is also studied in Fig. 5. In this analysis, four standard commercial materials including Rogers RT 6010 $\left(\varepsilon_{\mathrm{r}}=10.2, \tan \delta=0.0023\right)$, RO $3006\left(\varepsilon_{\mathrm{r}}=6.15, \tan \delta=0.0020\right)$, FR4 $\left(\varepsilon_{\mathrm{r}}=4.55, \tan \delta=0.0175\right)$, and Duroid $5880\left(\varepsilon_{\mathrm{r}}=2.2, \tan \delta\right.$ $=0.0009)$ have been adopted to represent four level variations of the permittivity. Notably, the antenna geometry parameters were re-optimized for each given substrate in Fig.5 to achieve the sharpest notch while maintaining a sufficient wide notched bandwidth. As can be observed, applying the material with a high permittivity can achieve good band-notched performance with VSWR better than 91 at the notched frequency. It is also found that with FR4 material, the antenna has lower signal rejection level than that using Duroid 5880, even though FR4 has a higher permittivity. This is caused by the high dielectric loss of FR4. Furthermore, one prototype of Antenna I_W using RT 6010 is fabricated (as shown in Fig. 14(a)), measured and compared in Fig. 5. Both results confirm that, a wide notched

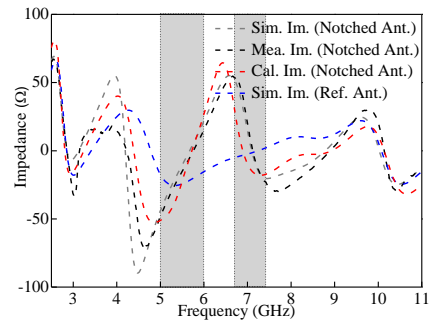

(a)

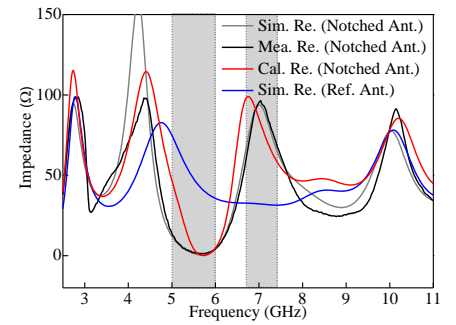

(b)

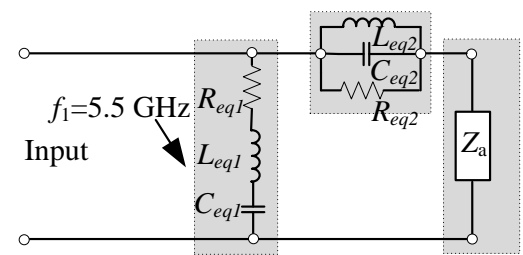

(c)

Fig. 6 Impedances of Antenna I_W, (a) Imaginary part, (b) Real part, and (c) Equivalent $L C$-circuit model. $R_{\text {eq } 1}=0.1 \mathrm{Ohm}, L_{\text {eq } 1}=7.7 \mathrm{nH}, C_{\text {eq } 1}=0.1 \mathrm{pF}$, $R_{\text {eq } 2}=117.8 \mathrm{Ohm}, L_{\mathrm{eq} 2}=0.46 \mathrm{nH}, C_{\mathrm{eq} 2}=1.6 \mathrm{pF}, \mathrm{Za}$ is the complex input impedance of the reference antenna.

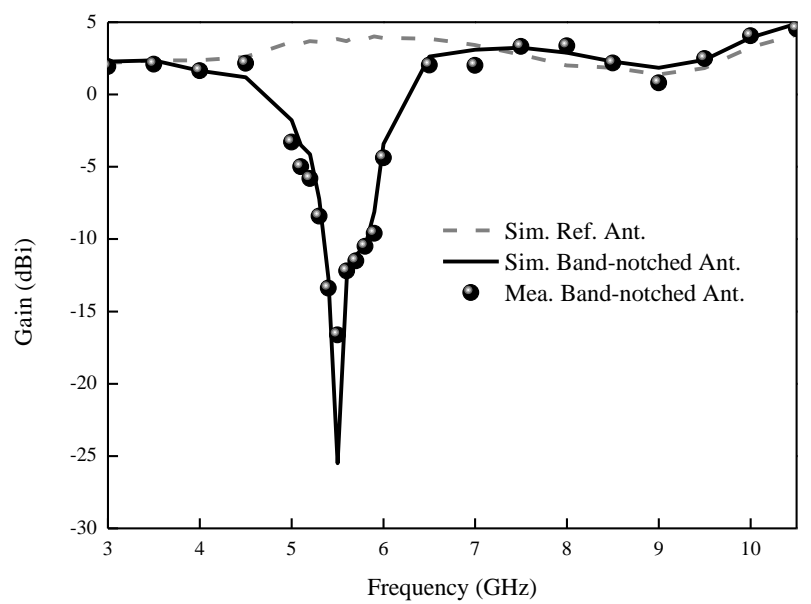

Fig. 7 Simulated and measured gain responses of Antenna I_W.

band in 4.6-6.4 GHz for $\left|S_{11}\right| \geq-5 \mathrm{~dB}$ is obtained and the result with $\left|S_{11}\right| \leq-10 \mathrm{~dB}$ is achieved at other passband frequencies. It should be noted that with this design, there is no need to 
re-optimize the other geometry parameters after the strips are connected to the signal line of the reference antenna. The simulated and measured impedance curves of Antenna I_W and reference antenna are plotted in Fig. 6(a)-(b) to further explain the operating principle of the band-rejected element. Compared to the reference antenna, two resonances are introduced after adding the horizontal strips to the reference UWB antenna. At $5.5 \mathrm{GHz}$, the imaginary component curve of the band-notched antenna exhibits a series resonance characteristic and the real component is close to zero. While at $7 \mathrm{GHz}$, the imaginary component curve shows a parallel resonance characteristic and the real part has a peak around $100 \mathrm{Ohm}$. The corresponding conceptual equivalent circuit model is shown in Fig. 6(c), in which a parallel $R L C$ resonant circuit is connected with $Z_{\mathrm{a}}$ in series, and then connected in parallel with a series $R L C$ resonant circuit. $Z_{\mathrm{a}}$ represents the complex input impedance of the reference antenna. $R_{\text {eqi }}, L_{\text {eqi }}$ and $C_{\text {eqi }}(i=1,2)$ are the resistor, inductor and capacitor values of the series and parallel resonant circuits respectively. When $l_{1}$ is equal to $\lambda_{\mathrm{g}} / 4\left(\lambda_{\mathrm{g}}\right.$ is the guided wavelength), the antenna is operating at the notched frequency $(5.5 \mathrm{GHz})$. The series resonant circuit will be syntonic, which leads the input to be shorted. Consequently, the antenna can't radiate at this frequency. However, the parallel resonance at 7 $\mathrm{GHz}$ has minor effect on the impedance matching performance (better than $-10 \mathrm{~dB}$ ) as the real part of the impedance is higher than the corresponding value of the reference antenna, as illustrated in Fig.5 and Fig.6(b).

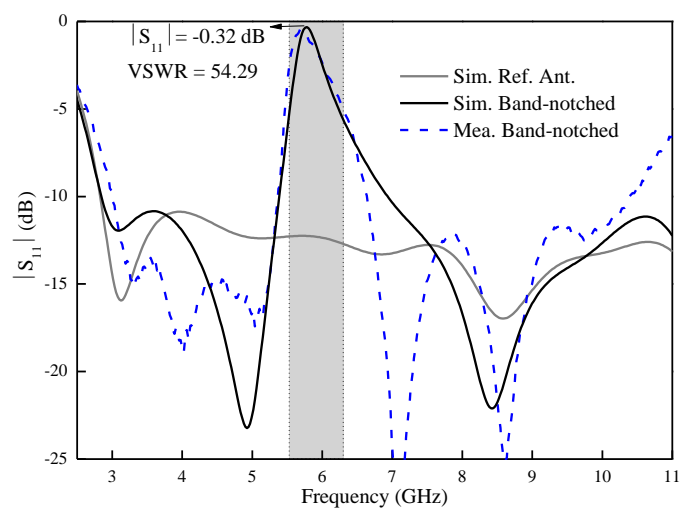

Fig. 8 Comparison between simulated and measured $\left|S_{11}\right|$ for Antenna I_N.

To predict the bandwidth of the series resonant circuit in Fig. 6(c), the resistance $R_{\mathrm{S}}$ of the series resonant circuit is given by

$$
R_{s}=R_{e q 1}+j \omega_{s} L_{e q 1}+\frac{1}{j \omega_{s} C_{e q 1}}
$$

For a frequency near the resonant frequency $\left(\omega_{\mathrm{s} 0}\right)$

$$
\begin{gathered}
\omega_{s}=\omega_{s 0}+\Delta \omega_{s}, \omega_{s 0}=\frac{1}{\sqrt{L_{e q 1} C_{e q 1}}} \\
R_{s}=R_{e q 1}+\frac{1-\omega_{s}^{2} L_{e q 1} C_{e q 1}}{j \omega_{s} C_{e q 1}} \\
=R_{e q 1}+\frac{j}{\omega_{s} C_{e q 1}}\left(\Delta \omega_{s}^{2}+2 \omega_{s 0} \Delta \omega_{s}\right) L_{e q 1} C_{e q 1}
\end{gathered}
$$

$$
\approx R_{e q 1}+j 2 L_{e q 1} \Delta \omega_{s}
$$

Thus, $R_{\mathrm{S}}$ is similar to the input impedance of a series $R$ and $2 L$. The $-3 \mathrm{~dB}$ bandwidth (BW) of the series $R L C$ resonant circuit is approximately equal to twice the $-3 \mathrm{~dB}$ BW of the series $R$ and $2 L$ circuit and this can be given by:

$$
B W_{s}=2 \frac{R_{e q 1}}{2 L_{e q 1}}=\frac{R_{e q 1}}{L_{e q 1}}
$$

As for the parallel resonant circuit, the resonant frequency and bandwidth can be predicted by using the formulas given in [28]:

$$
\begin{aligned}
& \omega_{p 0}=\frac{1}{\sqrt{L_{e q 2} C_{e q 2}}} \\
& B W_{p}=\frac{1}{R_{e q 2} C_{e q 2}}
\end{aligned}
$$

The proposed equivalent circuit model is validated by using the following steps. First, the initial values of $R_{\text {eqi }}, L_{\text {eqi }}$ and $C_{\text {eqi }}$ $(i=1,2)$ can be calculated by using the equations (4)-(7). After that, the equivalent circuit is built, tuned and optimized in ADS 2009 software package. The calculated input impedance of the equivalent circuit is compared in Fig. 6(a)-(b), in which a reasonable agreement can be observed.

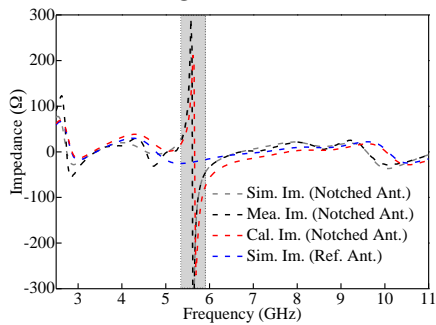

(a)

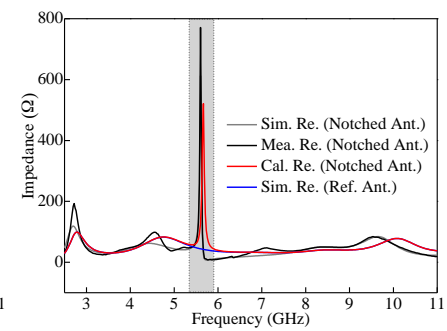

(b)

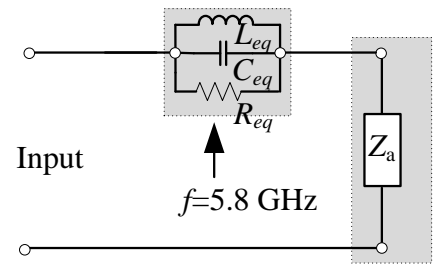

(c)

Fig. 9 (a) Simulated and measured impedances of Antenna I_N, (a) Imaginary part, (b) Real part and (c) equivalent LC-circuit model. $R_{\text {eq } 1}=496.8 \mathrm{Ohm}$, $L_{\mathrm{eq} 1}=0.14 \mathrm{nH}$, and $C_{\mathrm{eq} 1}=5.64 \mathrm{pF}$.

The simulated and measured peak gain for the band-notched antenna and reference antenna is illustrated in Fig. 7. The measurement was carried out in a fully calibrated anechoic chamber with the loss being taken into consideration. The connecting cable attached to the antenna was covered by electromagnetic wave absorber to minimize the potential interferences. As observed, the signal attenuation is better than $15 \mathrm{~dB}$ at the notched frequency. Moreover, the variation of the gain is less than $5 \mathrm{~dB}$ over the entire operating band, indicating nearly omni-directional radiation which is required for UWB terminals in wireless applications. 


\section{B. UWB Antenna with Narrow Band-Notched Function (Antenna I_N)}

Compared to Antenna I_W, a narrow band-notched antenna (denoted as Antenna I_N) aiming to reject the frequency band in $5.725-5.825 \mathrm{GHz}$ will be discussed and investigated in this section. The configuration and the prototype photo of Antenna I_N are shown in Fig. 1(b) and Fig. 14(b), respectively. By embedding two quarter-wavelength open-ended slots with length $l_{2}$ and width $g_{2}$ in the feed line, an additional resonance can be introduced to the antenna response, which causes the antenna to be nonresponsive at the desired rejected frequency. The optimized values of the slot and stub assuming $f_{\mathrm{n}}=5.8 \mathrm{GHz}$ are as follows: $l_{2}=5.3 \mathrm{~mm}, w_{2}=0.6 \mathrm{~mm}$, and $g_{2}=0.4 \mathrm{~mm}$.

The simulated and measured reflection coefficients for the band-notched design and reference UWB antenna are compared in Fig. 8. For the reference antenna, the impedance bandwidth defined by $\left|\mathrm{S}_{11}\right| \leq-10 \mathrm{~dB}$ is ranging from 2.86 to $11 \mathrm{GHz}$. Compared to the reference antenna, the notched design (Antenna I_N) can block out the frequency band in 5.55-6.25 $\mathrm{GHz}$ for $\left|\mathrm{S}_{11}\right| \geq-5 \mathrm{~dB}$, and still perform good impedance matching at other frequencies in the UWB band. It is also interestingly found that the $\left|\mathrm{S}_{11}\right|$ at $5.8 \mathrm{GHz}$ is $-0.32 \mathrm{~dB}$ which is corresponding to 54.29 of VSWR.

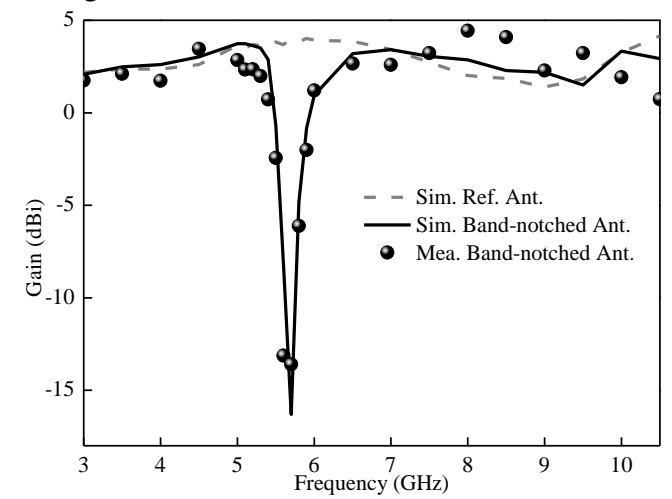

Fig. 10 Simulated and measured gain responses of Antenna I_N.

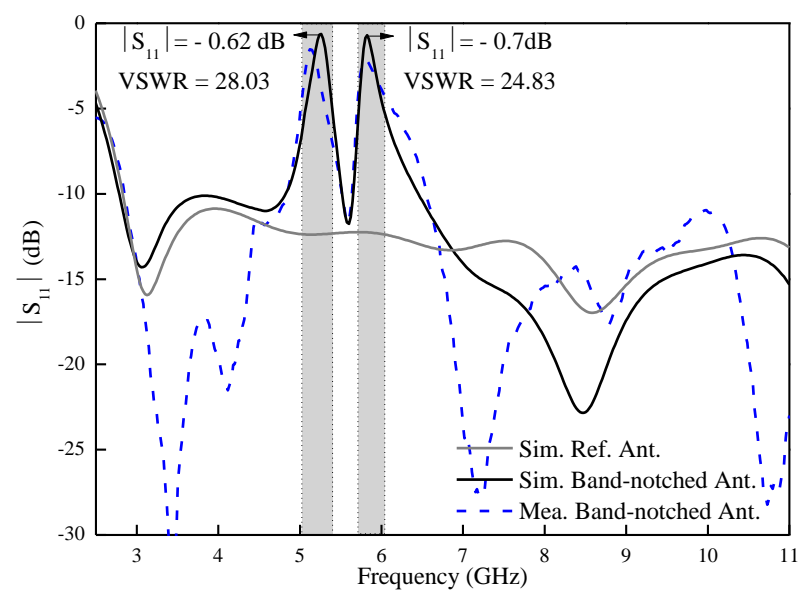

Fig. 11 Comparison between simulated and measured $\left|S_{11}\right|$ for Antenna II.

The simulated and measured impedance curves of Antenna I_N and reference antenna are shown in Fig. 9(a)-(b). Compared to the reference antenna, the imaginary component curve of the band-notched antenna exhibits the parallel resonance characteristic and the real component is over $500 \mathrm{Ohm}$ at the notched frequency. The corresponding conceptual equivalent circuit model is shown in Fig. 9(c), in which a parallel $R L C$ resonant circuit is connected with $Z_{\mathrm{a}}$ in series. When $l_{2}$ is equal to $\lambda_{\mathrm{g}} / 4$, the antenna is operating at the notched frequency. The $R L C$-resonant circuit will be resonant, which leads the input to be opened. Hence, the radiation can't be generated by the antenna at this frequency. By using the design approach in the previous section, the calculated input impedance of Antenna I_N is compared in Fig. 9(a)-(b). The calculated impedance has the same trend as the simulated one, though the real part at the notched frequency is slightly lower. The simulated and measured peak gain of the band-notched antenna and reference antenna is shown in Fig. 10. A significant gain suppression of around $15 \mathrm{~dB}$ is obtained in the notched band.

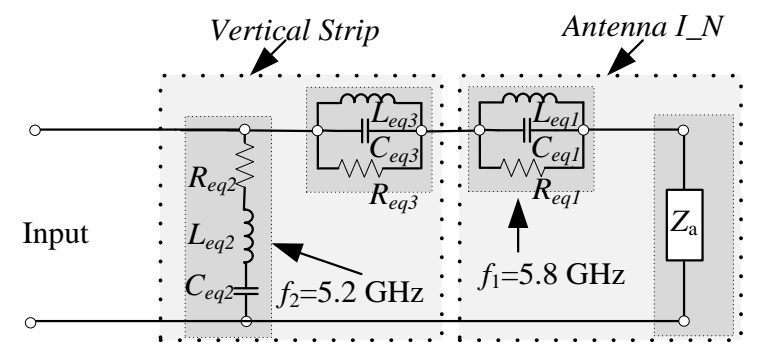

(a)

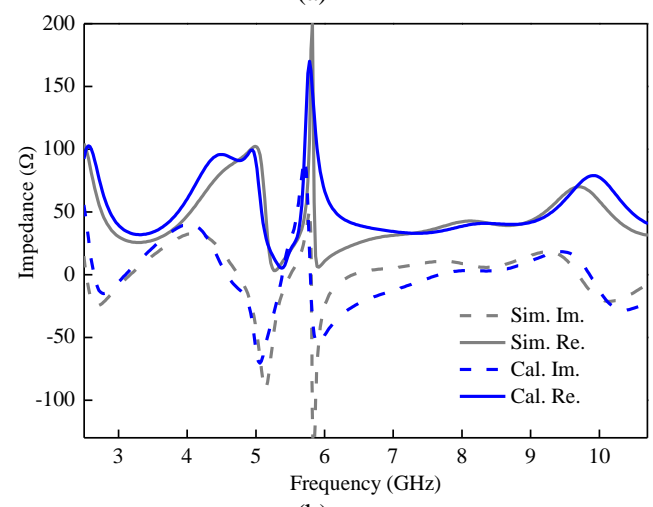

(b)

Fig. 12. (a) Equivalent circuit model of Antenna II, and (b) Comparison of input impedance between simulation and calculation. $R_{\text {eq1 }}=160.2 \mathrm{Ohm}$, $L_{\text {eq } 1}=0.09 \mathrm{nH}, C_{\text {eq } 1}=8.6 \mathrm{pF}, R_{\text {eq } 2}=5.5 \mathrm{Ohm}, L_{\mathrm{eq} 2}=28.4 \mathrm{nH}, C_{\text {eq } 2}=0.03 \mathrm{pF}$, $R_{\text {eq } 3}=93.5 \mathrm{Ohm}, L_{\mathrm{eq} 3}=0.12 \mathrm{nH}$, and $C_{\mathrm{eq} 3}=7.5 \mathrm{pF}$.

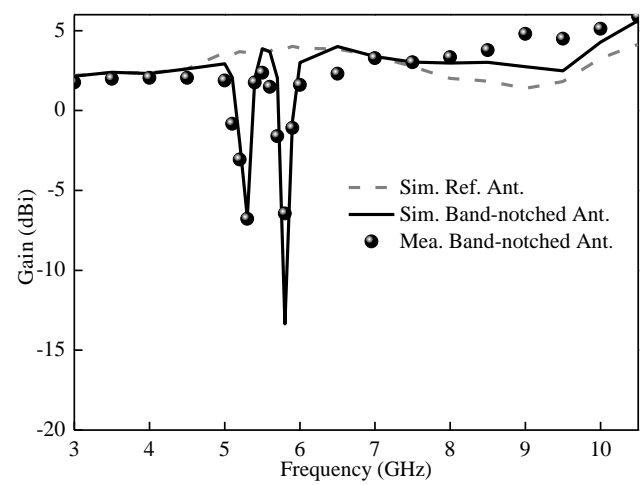

Fig. 13 Simulated and measured gain responses of Antenna II. 


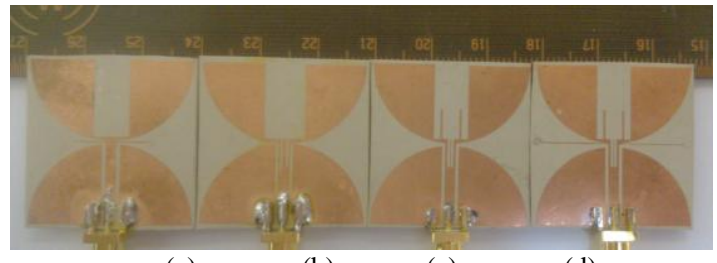

(a)

(b)

(c)

(d)

Fig. 14 Photos of fabricated prototypes. (a) Antenna I_W, (b) Antenna I_N, (c) Antenna II, and (d) Antenna III.

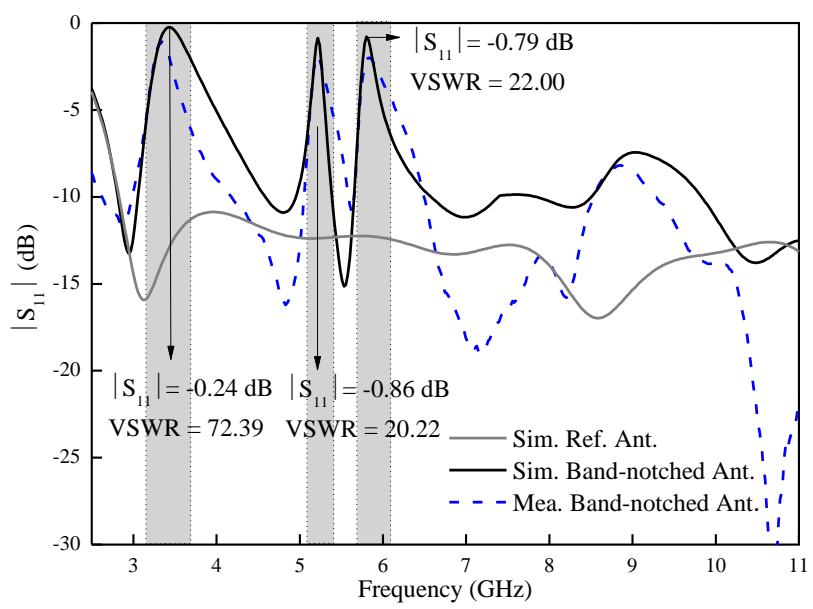

Fig. 15 Comparison between simulated and measured $\left|S_{11}\right|$ of Antenna III.

\section{MulTiPle BAND-NOTCHED UWB ANTENNA DESIGN}

By combining the design concepts of the two single band-notched antennas, this section will further extend and investigate these approaches to the multiple band-notched designs.

\section{A. UWB Antenna with Dual Band-Notched Function (Antenna II)}

Antenna I_W can perform the wide band-notched function covering both the lower and upper WLAN bands. While in some cases, the dual band-notched UWB antennas are required to reject each band separately. Based on the design of Antenna I_N, the dual band-notched design (Antenna II) can be achieved by adding additional stubs in the rectangular slot to reject the lower WLAN band from 5.15-5.35 GHz. The geometry of Antenna II is shown in Fig. 1(c), and the photo of the prototype is depicted in Fig. 14(c). The vertical stubs are symmetrically placed to the center line of the structure. The operating principle of the vertical stub is similar to that of the horizontal stub in Antenna I_W at the notched frequency. The lower and upper WLAN bands are rejected by the vertical stubs and open-ended slots, respectively. The optimized values of the dimensions are as follows: $w_{2}=0.3 \mathrm{~mm}, g_{2}=0.4 \mathrm{~mm}, l_{2}=5.2 \mathrm{~mm}, w_{3}=0.4 \mathrm{~mm}$, $g_{3}=1.1 \mathrm{~mm}$ and $l_{3}=5.6 \mathrm{~mm}$. The simulated and measured reflection coefficients are demonstrated in Fig. 11. It is clearly shown that, the operating frequency of Antenna II is ranging from 2.8 to $11 \mathrm{GHz}$ with the frequency bands in $5-5.35 \mathrm{GHz}$ and $5.7-6.1 \mathrm{GHz}$ for $\left|S_{11}\right| \geq-5 \mathrm{~dB}$ are notched. The highest $\left|S_{11}\right|$ for the lower and upper notched bands are $-0.62 \mathrm{~dB}$ and $-0.7 \mathrm{~dB}$ which are equivalent to 28.03 and 24.83 of VSWR respectively.
The equivalent circuit model is shown in Fig. 12(a). It can be regarded as the combination of Antenna I_N and the vertical strips. Since the vertical and horizontal strips have similar operating mechanism, the equivalent circuit of the vertical strips is formed by a series $R L C$ resonant circuit and a parallel $R L C$ resonant circuit, in which the series $R L C$ resonant circuit will cause the notched frequency at 5.2 GHz. The calculated and simulated impedance curves are shown in Fig. 12(b). An acceptable agreement can be observed.

Fig. 13 illustrates the measured peak gain for Antenna II alongside that of the reference antenna. According to the measured result, it is obvious that the gain reductions in the dual notched bands are around $10 \mathrm{~dB}$.

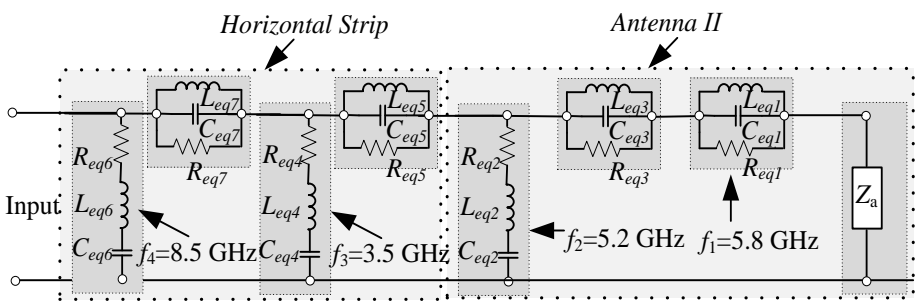

(a)

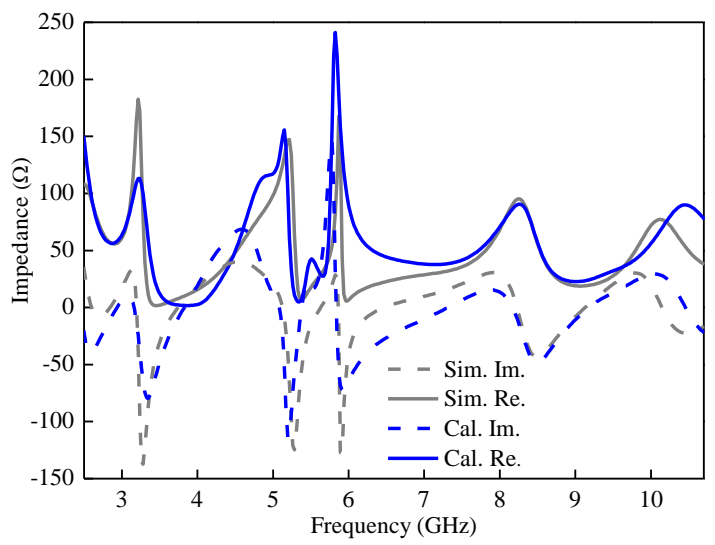

(b)

Fig. 16. (a) Equivalent circuit model of Antenna III, and (b) Comparison of input impedance curves between simulation and calculation. $R_{\text {eq1 }}=259.74$ Ohm, $L_{\text {eq } 1}=0.07 \mathrm{nH}, C_{\text {eq } 1}=9.9 \mathrm{pF}, R_{\text {eq } 2}=1.62 \mathrm{Ohm}, L_{\mathrm{eq} 2}=31.3 \mathrm{nH}, C_{\text {eq } 2}=0.03 \mathrm{pF}$, $R_{\text {eq } 3}=100.87 \mathrm{Ohm}, L_{\mathrm{eq} 3}=0.09 \mathrm{nH}, C_{\text {eq } 3}=9.7 \mathrm{pF}, R_{\text {eq } 4}=1.71 \mathrm{Ohm}, L_{\text {eq }}=8.3 \mathrm{nH}$, $C_{\text {eq } 4}=0.18 \mathrm{pF}, R_{\text {eq } 5}=200 \mathrm{Ohm}, L_{\text {eq } 5}=0.7 \mathrm{nH}, C_{\text {eq }}=2.2 \mathrm{pF}, R_{\text {eq } 6}=26.65 \mathrm{Ohm}$, $L_{\text {eq } 6}=6.9 \mathrm{nH}, C_{\text {eq } 6}=0.04 \mathrm{pF}, R_{\text {eq } 7}=90 \mathrm{Ohm}, L_{\text {eq } 7}=0.15 \mathrm{nH}$, and $C_{\text {eq }}=2.1 \mathrm{pF}$.

\section{B. UWB Antenna with Triple Band-Notched Function (Antenna III)}

In addition to the WLAN systems operating in 5.15-5.35 $\mathrm{GHz}$ and 5.725-5.825 GHz, the WiMAX band (3.3-3.6 GHz) may also cause potential interference within the UWB band. Hence, a triple band-notched design (denoted as Antenna III) is required to settle this problem. Based on the design of the dual band-notched design (Antenna II), another notched band can be obtained by adding a pair of horizontal stubs. This is similar with Antenna I_W, in which the straight stubs are horizontally connected to the signal line. Fig. 1(d) shows the geometry of Antenna III. Thus, the desired notched bands in $3.3-3.6 \mathrm{GHz}$, 5.15-5.35 GHz, and 5.725-5.825 GHz can be realized by employing the horizontal stubs, vertical stubs and open-ended slots respectively. Moreover, the dimensions of the vertical slots 
and stubs remain the same as in Antenna II. The only difference between Antenna III and Antenna II is to tune the dimensions of the horizontal stubs. The optimized values of its dimensions are as follows: $l_{1}=12.5 \mathrm{~mm}$, and $w_{1}=0.3 \mathrm{~mm}$. The fabricated prototype of the antenna is depicted in Fig. 14(d).
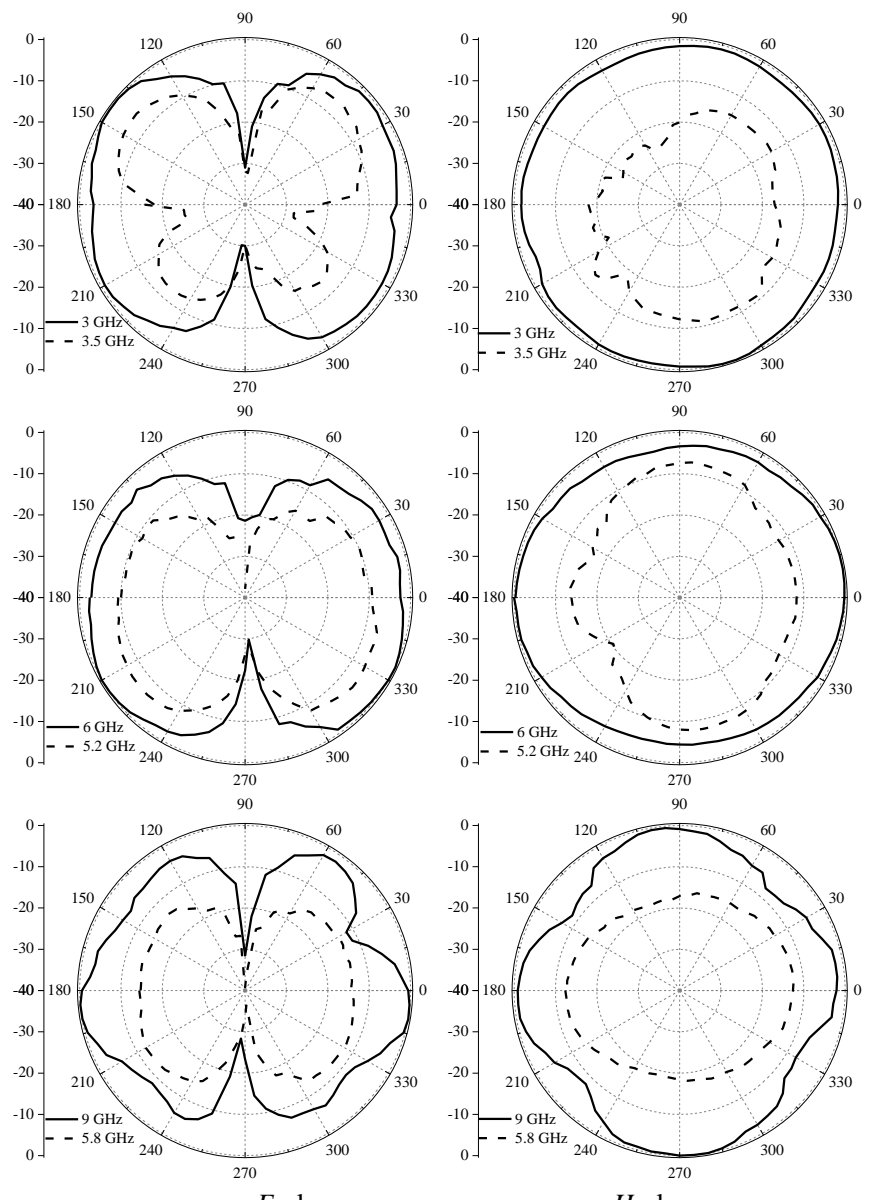

E-plane

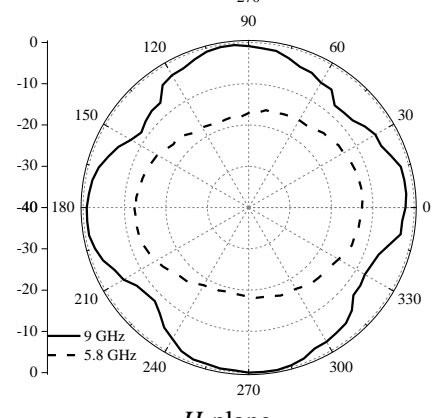

$H$-plane

Fig. 17 Measured radiation patterns for Antenna III at different frequencies.

The simulated and measured reflection coefficients for Antenna III and the reference antenna are demonstrated in Fig. 15. The measured result suggests that, the frequency range of Antenna III is ranging from 3 to over $11 \mathrm{GHz}$ and three frequency bands in $3.15-3.62 \mathrm{GHz}, 5.1-5.38 \mathrm{GHz}$, and 5.72-6.12 GHz for $\left|\mathrm{S}_{11}\right| \geq-5 \mathrm{~dB}$ are notched within the UWB band. The corresponding highest $\left|S_{11}\right|$ at these notched bands are $-0.24 \mathrm{~dB},-0.86 \mathrm{~dB}$ and $-0.79 \mathrm{~dB}$ which represent $72.39,20.22$ and 22 of VSWR values respectively. It is also noted that, a spurious notched band has emerged near $8.5 \mathrm{GHz}$. The equivalent $L C$-circuit model is shown in Fig. 16(a). It can be regarded as the combination of Antenna II and the horizontal strips. The equivalent circuit of the horizontal strips consists of two series resonant circuits and two parallel resonant circuits. Two series resonant circuits are resonating at 3.5 and $8.5 \mathrm{GHz}$, and cause the notched frequencies. In addition, two parallel resonant circuits are operating near 3.5 and $8.5 \mathrm{GHz}$, but will not induce notched bands. Fig. 16(b) presents the comparison of the input impedance between simulation and calculation. Referring to the figure, the trends of the curves agree reasonably well over the whole UWB band.
The measured co-polarized radiation patterns in the $E$ - and $H$-planes at different frequencies are illustrated in Fig. 17. As observed, the radiation pattern is bidirectional in the $E$-plane and omnidirectional in the $\mathrm{H}$-plane at $3 \mathrm{GHz}$. It can be regarded as a monopole which features a doughnut-shaped pattern at the fundamental mode. As the operating frequency increases, the radiation pattern in the $H$-plane is quasi-omnidirectional and remains bidirectional in the $E$-plane at $6 \mathrm{GHz}$. It is also noticed that the pattern in the $H$-plane is similar to the shape of a

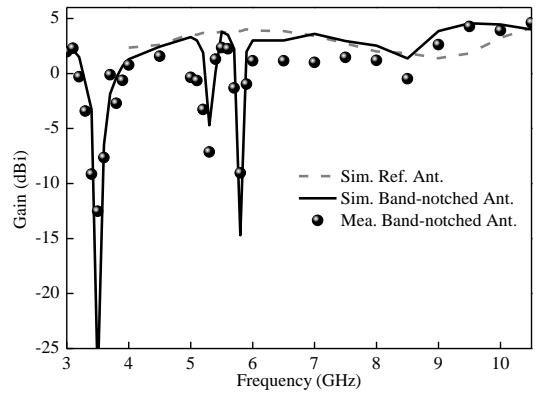

Fig. 18 Simulated and measured gain responses of Antenna III.

four-leaved clover when operating at the higher-order mode $(9 \mathrm{GHz})$. The co-polarization at the notched frequencies is much lower than that of the operating frequencies.

The comparison of the gain response between simulation and measurement for Antenna III and reference antenna is depicted in Fig. 18 to show its band-notched performance. Compared to the reference antenna, the triple band-notched antenna performs significant gain suppression within the notched bands, while the inclusion of the band-rejected elements causes little impact on the gain response at other frequencies outside the notched band. As shown in Fig. 18, the gain reduction in the notched bands is ranging from $10 \mathrm{~dB}$ to over $15 \mathrm{~dB}$.

\section{CONCLUSION}

In this paper, four novel band-notched UWB antennas (Antenna I_W, Antenna I_N, Antenna II, and Antenna III) have been presented. These antennas can avoid the interferences from WiMAX (3.3-3.6 GHz) or WLAN $(5.15-5.35 \mathrm{GHz}$ and $5.725-5.825 \mathrm{GHz}$ ) systems and remove the requirement on additional band-stop filters. The band-notched characteristics are obtained by introducing the quarter-wavelength band-rejected elements in the planar UWB antenna. Compared to existing UWB antennas utilizing half-wavelength band-rejected elements, the quarter-wavelength band-rejected elements employed in the design have the benefit of smaller dimensions and simple structure, thus suitable for multiple band-notched designs. It is found that, good band-notched performance can be realized by integrating the band-rejected elements in the signal line and adopting high permittivity substrate. The proposed single and multiple band-notched designs can achieve a wide or narrow notched band and a high level of signal rejection. Moreover, the equivalent circuits of the proposed antennas were also studied and validated. 


\section{ACKNOWLEDGEMENT}

The authors wish to thank Dr. Neil J. McEwan from University of Bradford, UK for suggestions and valuable discussions.

\section{REFERENCES}

[1] P. Li, J. Liang, and X. D. Chen, "Study of printed elliptical/circular slot antennas for ultrawideband applications," IEEE Trans. Antennas Propag., vo. 54, no. 6, 2006, pp. 1670-1675.

[2] Z. N. Chen, M. J. Ammann, X. M. Qing, X. H. Wu, T. S. P. See, and A. L. Cai, "Planar antennas," IEEE Microw. Mag., vol. 7, 2006, pp. 63-73.

[3] H. G. Schantz, "A brief history of UWB antennas," IEEE A\&E Syst. Mag., vol. 19, no. 4, 2004, pp. 22-26.

[4] C. C. Lin, P. Jin, and R. W. Ziolkowski, "Single, dual and tri-band-notched ultrawideband antennas using capacitively loaded loop resonators," IEEE Trans. Antennas Propag., vol. 60, no. 1, 2012.

[5] A. Kerkhoff, and H. Ling, "Design of a planar monopole antenna for use with ultra-wideband (UWB having a band-notched characteristic," in IEEE AP/S Int. Symp. Dig., vol, 1, 2003, pp. 830-833.

[6] H. G. Schantz, G. Wolenec, and E. Myszka, "Frequency notched UWB antennas," in Proc. IEEE Conf. Ultra Wideband Syst. Technol., 2003.

[7] Y. J. Cho, K. H. Kim, D. H. Choi, S. S. Lee, and S. O. Park, "A miniature UWB planar monopole antenna with 5-GHz band-rejection filter and the time-domain characteristics," IEEE Trans. Antennas Propag., vol. 54, no. 5, 2006, pp. 1453-1460.

[8] J. Y. Sze, and J. Y. Shiu, "Design of band-notched ultrawideband square aperture antenna with a hat-shaped back-patch," IEEE Trans. Antennas Propag., vol. 56, no. 10, 2008, pp. 3311-3314.

[9] Y. C. Lin, and K. J. Hung, "Compact ultra-wideband rectangular aperture antenna and band-notched designs," IEEE Trans. Antennas Propag., vol. 54, no. 11, 2006, pp. 3075-3081.

[10] C. Y. Huang, W. C. Hsia, and J. S. Kuo, "Planar ultra-wideband antenna with a band-notched characteristic," Microwave Opt. Technol. Lett., vol. 48. no. 1, 2005, pp. 99-101.

[11] A. M. Abbosh, M. E. Bialkowski, J. Mazierska, and M. V. Jacob, "A planar UWB antenna with signal rejection capability in the 4-6 GHz band," IEEE Microw. Wireless Compon. Lett., vol. 16, no. 5, 2006.

[12] Z. A. Zheng, Q. X. Chu, and Z. H. Tu, "Compact band-rejected ultrawideband slot antennas inserting with $\lambda / 2$ and $\lambda / 4$ resonators," IEEE Trans. Antennas Propag., vol. 59, no. 2, 2011, pp. 390-397.

[13] I. J. Yoon, H. Kim, H. K. Yoon, Y. J. Yoon, and Y. H. Kim, "Ultra-wideband tapered slot antenna with band cutoff characteristic," Electron. Lett., vol. 41, no. 11, 2005, pp. 629-630.

[14] K. H. Kim, Y. J. Cho, S. H. Hwang, and S. O. Park, "Band-notched UWB planar monopole antenna with two parasitic patches," Electron. Lett., vol. 41, no. 14, 2005, pp. 783-784.

[15] K. H. Kim, and S. O. Park, "Analysis of the small band-rejected antenna with the parasitic strip for UWB," IEEE Trans. Antennas Propag., vol. 54, no. 6, 2006, pp. 1688-1692.

[16] Q. X. Chu, and T. G. Huang, "Compact UWB antenna with sharp band-notched characteristics for lower WLAN band," Electron. Lett., vol. 47, no. 15,2011 , pp. 838-839.

[17] K. G. Thomas, and M. Sreenivasan, "A simple ultrawideband planar rectangular printed antenna with band dispensation," IEEE Trans. Antennas Propag., vol. 58, no. 1, 2010, pp. 27-34.

[18] M. Yazdi, and N. Komjani, "Design of a band-notched UWB monopole antenna by means of an EBG structure," IEEE Antennas Wireless Propag. Lett., vol. 10, 2011, pp. 170-173.

[19] C. Y. Huang, and J. Y. Su, "A printed band-notched UWB antenna using quasi-self-complementary structure," IEEE Antennas Wireless Propag. Lett., vol. 10, 2011, pp. 1151-1153.

[20] X. L. Bao, and M. J. Ammann, "Printed UWB antenna with coupled slotted element for notch-frequency function," Int. J. Antennas Propagat., vol. 2008, Article ID 713921, 2008.

[21] K. S. Ryu, and A. A. Kishk, "UWB antenna with single or dual band-notches for lower WLAN band and upper WLAN band," IEEE Trans. Antennas Propag., vol. 57, no. 12, 2009, pp. 3942-3950.

[22] Q. X. Chu, and Y. Y. Yang, "A compact ultrawideband antenna with 3.4/5.5 GHz dual band-notched characteristics," IEEE Trans. Antennas Propag., vol. 56, no. 12, 2008, pp. 3637-3644.
[23] W. S. Chen, and K. Y. Ku, "Band-rejected design of the printed open slot antenna for WLAN/WiMAX operation," IEEE Trans. Antennas Propag., vol. 56, no. 4, 2008, pp. 1163-1169.

[24] T. D. Nguyen, D. H. Lee, and H. C. Park, "Design and analysis of compact printed triple band-notched UWB antenna," IEEE Antennas Wireless Propag. Lett., vol. 10, 2011, pp. 403-406.

[25] L. Peng, and C. L. Ruan, "UWB band-notched monopole antenna design using electromagneitc-bandgap structures," IEEE Trans. Microw. Theory Tech., vol. 59, no. 4, 2011, pp. 1074-1081.

[26] Y. D. Dong, W. Hong, Z. Q. Kuai, C. Yu, Y. Zhang, J. Y. Zhou, and J. X. Chen, "Development of ultrawideband antenna with multiple band-notched characteristics using half mode substrate integrated waveguide cavity technology," IEEE Trans. Antennas Propag., vol. 56, no. 9, 2008, pp. 2894-2902.

[27] T. G. Ma, and S. J. Wu, "Ultrawideband band-notched folded strip monopole antenna," IEEE Trans. Antennas Propag., vol. 55, no. 9, 2007.

[28] Y. D. Dong, W. Hong, Z. Q. Kuai, and J. X. Chen, "Analysis of planar ultrawideband antennas with on-ground slot band-notched structures," IEEE Trans. Antennas Propag., vol. 57, no. 7, pp. 1886-1893, 2009.

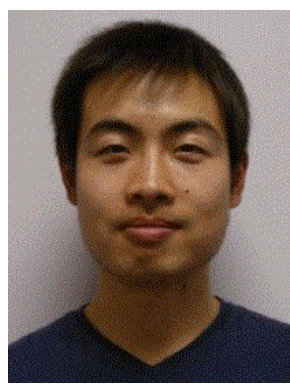

Fuguo Zhu was born in Jiangsu, China, in 1986. He received his M.Sc. degree in electromagnetic theory and microwave technology from Northwestern Polytechical University, P.R. China, in 2011. He is currently working towards the Ph.D. degree at Surrey Space Centre, University of Surrey, UK. His research interests include UWB antenna, dual-polarized UWB antenna, and UWB antenna array.

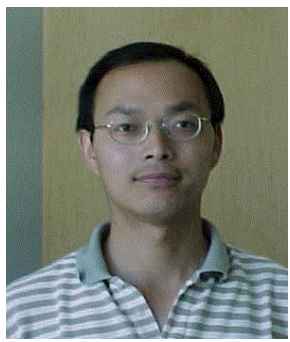

Steven Gao (M'01) was born in Tianchang, Anhui, P.R. China. He received the Ph.D. degree in microwave engineering from Shanghai University, Shanghai, China, in 1999.

$\mathrm{He}$ is a Professor in antennas and microwave/millimetre-wave systems at University of Kent, UK. His research covers space antennas, smart antennas, phased arrays, millimetre-wave antennas, high-efficiency $\mathrm{RF} /$ microwave power amplifiers, satellite communications, UWB radars, synthetic-aperture radars, EM modelling and small satellites (micro-satellite, mini-satellite, nano-satellite). He was a Senior Lecturer and Head of Space Antennas and Microwave System Group at Surrey Space Center, University of Surrey, UK. He also worked at other institutes internationally, including as a Researcher at China Research Institute of Radiowave Propagation (China), a Post-doctoral Research Fellow at National University of Singapore (Singapore), a Research Fellow at Birmingham University (UK), a Visiting Scientist at Swiss Federal Institute of Technology (ETHZ, Switzerland), a Visiting Fellow at Chiba University (Japan), a Visiting Scientist at University of California at Santa Barbara (US), and a Senior Lecturer/Reader/Head of Antenna and Microwave Group at Northumbria University (UK).

$\mathrm{He}$ is General Chair of Loughborough Antennas and Propagation International Conference, UK, 2013, and Chair of Special Session on "Satellite Communication Antennas" in IEEE/IET International Symposium on Communication Systems and Networks, Poland, 2012, etc. He is a co-editor of <<Space Antenna Handbook〉> (Wiley, 2012), published over 160 technical papers, 8 book chapters and holds several patents in smart antennas and RF. He received "URSI Young Scientist Award" from International Union of Radio Science, 2002, "Japan Society of Promotion Science Fellowship Award", Japan, 2005, "Best Paper Award", LAPC, UK, 2012, etc. He has been a Principal Investigator for many projects including "Millimeter-wave intelligent array antennas for next-generation mobile satellite communications" (FLEXWIN, funded by European Union FP7 ICT Program), etc.

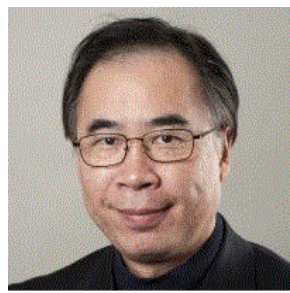

Anthony T.S. Ho is currently Head of Department of Computing, University of Surrey. He was the recipient of the prestigious Institution of Engineering and Technology (IET) Innovation in Engineering Award under the Security category for 
his research and commercialization work on digital watermarking in 2006

Professor Ho obtained his BSc (Hons) in Physical Electronics from Northumbria University in 1979, his MSc in Applied Optics from Imperial College London in 1980 and his PhD in Digital Image Processing from King's College London in 1983. He has published more than 120 articles in international journals and conference proceedings as well as 8 international patents granted related to watermarking and steganography.

Professor Ho is the Editor-in-Chief of the international journal Information Security Technical Report published by Elsevier. He is a Fellow of IET, Institute of Physics (FInstP), British Computer Society (FBCS) and Senior Member of IEEE

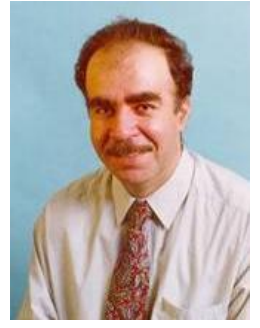

Raed A. Abd-Alhameed is a Professor of Electromagnetic and Radio Frequency (RF) Engineering in the School of Engineering, Design and Technology at the University of Bradford, UK. He has over 20 years' research experience in RF designs, antennas and electromagnetic computational techniques and has published over 400 academic journals and referred conference papers. He has led several funded projects from EPSRC, Health Department, Technology Strategy Board and Industry. $\mathrm{He}$ is the chair of several successful workshops on Energy Efficient and Reconfigurable Transceivers (EERT): Approach towards Energy Conservation and $\mathrm{CO}_{2}$ Reduction that addresses the biggest challenges for the future wireless systems. His current research interests include hybrid electromagnetic, EMC, low SAR antennas, active antennas, beam steering antennas, MIMO antennas, RF predistorter including biological cell modelling for breast cancer applications. He is the Fellow of the Institution of Engineering and Technology, Fellow of Higher Education Academy and a Chartered Engineer.

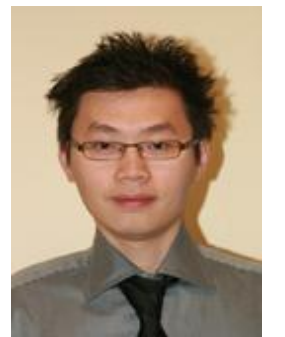

Chan H. See received a first class BEng Honours degree in Electronic, Telecommunication and Computer Engineering and a $\mathrm{PhD}$ degree from the University of Bradford, UK in 2002 and 2007 respectively. Currently, he is working as a senior research fellow in the Antennas and Applied Electromagnetics research group within the Electronics, Communications and Information Systems Engineering (ECISE), to support various projects related to sensors and antennas for the water industry. He has published over 100 journal articles and conference papers. $\mathrm{He}$ is a coauthor for 1 book and 1 book chapter. He was a recipient of two Young Scientist Awards from International Union of Radio Science (URSI) and Asia-Pacific Radio Science Conference (AP-RASC) in 2008 and 2010 respectively. Dr See is a Chartered Engineer and Member of the Institution of Engineering and Technology (MIET). He has an NVQ level 4 in Management from the Chartered Management Institute.

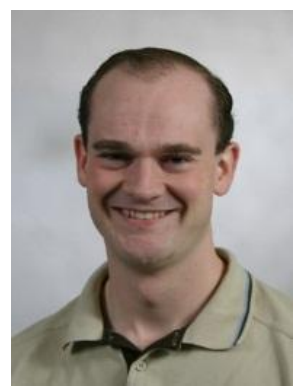

Tim WC Brown (SM'00-M'04) graduated from the University of Surrey in 1999 with a BEng in Electronic Engineering and since graduated with a $\mathrm{PhD}$ in antenna diversity for mobile terminals in the Centre for Communication Systems Research (CCSR) in 2004. Since completing his doctoral research, he has continued his research interests in antennas, propagation and radio frequency (RF) engineering. This has included postdoctoral research from 2004-2006 at Aalborg University, Denmark and his present post as a lecturer in RF, antennas and propagation at CCSR. His current research interests include mobile terminal antennas, satellite communications, multiple input multiple output (MIMO), ultra wideband (UWB) radar, radio frequency identification (RFID), near field communications (NFC), vehicular technologies and future wireless

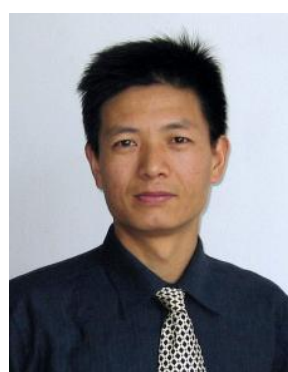

Jianzhou Li received the B.E., M.E. and Ph.D. degrees from Northwestern Polytechnical University, China in 1995, 2002 and 2005, respectively. From 2008 to 2009 , he was a visiting scholar at Surrey Space Centre, University of Surrey, UK. Currently he works as associate professor at School of Electronics and Information, Northwestern Polytechnical University, China. His research interests include computational electromagnetics and printed antennas.

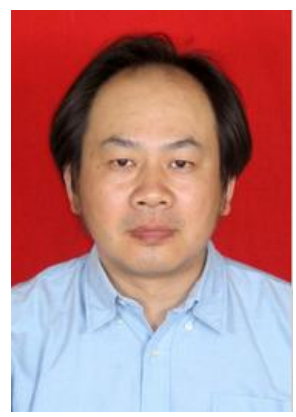

Gao Wei was born in Shaanxi, China, in 1963. He is a professor at School of Electronics and Information, Northwestern Polytechnical University, China. Since 1990, he has been with the School of electronic \& information Northwestern Polytechnical University, China. His research interests include microwave measurement, microwave communication and microwave application technology.

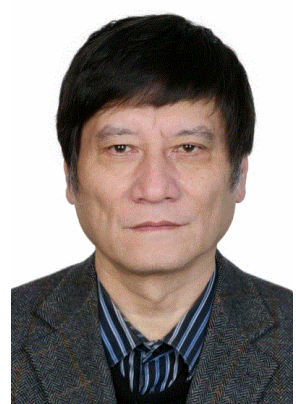

Jiadong Xu was born in Nanjing, China, in 1948. Since 1990, he has been with the School of Electronics and Information, Northwestern Polytechnical University, China, as a full professor working on antenna design, EM scattering theory and microwave measurement. 